\title{
Terapêutica não-farmacológica para alívio do ingurgitamento mamário durante a lactação: revisão integrativa da literatura
}

\author{
A NON-PHARMACOLOGIC TREATMENT TO RELIEVE BREAST ENGORGEMENT \\ DURING LACTATION: AN INTEGRATIVE LITERATURE REVIEW
}

TERAPÉUTICA NO FARMACOLÓGICA PARA ALIVIO DE LA INGURGITACIÓN MAMARIA
DURANTE LA LACTANCIA: REVISIÓN INTEGRAL DE LA LITERATURA

Ligia de Sousa', Mariana Lourenço Haddad ${ }^{2}$, Ana Márcia Spanó Nakano³, Flávia Azevedo Gomes ${ }^{4}$

\section{RESUMO}

O ingurgitamento mamário afeta a amamentação e causa o desmame precoce. A literatura apresenta técnicas de tratamento do ingurgitamento, entretanto há conflitos quanto à melhor terapêutica. $\mathrm{O}$ objetivo desta pesquisa é identificar e analisar as evidências encontradas na literatura da terapêutica não-farmacológica para alívio de sintomas de ingurgitamento mamário durante a amamentação. Foi realizada uma revisão integrativa da literatura com estudos publicados a partir de 1990, nas bases de dados MEDLINE e LILACS utilizando as palavras chaves: aleitamento materno, transtorno da lactação e terapia. Foram encontrados dez estudos, sendo dois de revisão sistemática da literatura, sete ensaios clínicos controlados randomizados e um estudo quase-experimental. Os estudos analisados apresentam resultados divergentes e não há evidências suficientes para recomendar a implementação dos tratamentos avaliados. São necessários mais estudos controlados randomizados para verificar terapias eficazes para o tratamento do ingurgitamento mamário.

\section{DESCRITORES}

Aleitamento materno

Transtornos da lactação

Terapêutica

\begin{abstract}
Breast engorgement affects breastfeeding and leads to early weaning. The literature presents techniques for treating engorgement, but there is no agreement as to which is the best treatment. The objective of this study is to identify and analyze the evidence found in the literature regarding non-pharmacological treatments to relieve breast engorgement symptoms during breastfeeding. We performed an integrative literature review of studies published since 1990, on MEDLINE and LILACS, using the keywords: breastfeeding, lactation disorder and therapy. We found ten studies: two systematic literature reviews, seven randomized controlled trials and one quasi-experimental study. The analyzed studies show conflicting results and there is not enough evidence to recommend the implementation of the evaluated treatments. Further randomized controlled trials are necessary to determine effective therapies for treating breast engorgement.
\end{abstract}

\author{
DESCRIPTORS \\ Breast feeding \\ Lactation disorders \\ Therapeutics
}

\begin{abstract}
RESUMEN
La ingurgitación mamaria afecta al amamantamiento y causa destete precoz. La literatura presenta técnicas de tratamiento de la ingurgitación, aunque hay divergencias respecto de la mejor terapéutica. Esta investigación objetiva identificar y analizar las evidencias encontradas en literatura acerca de terapéutica no farmacológica para alivio de síntomas de ingurgitación mamaria durante el amamantamiento. Se realizó una revisión integral de la literatura con estudios publicados desde 1990 en las bases MEDLINE y LILACS, utilizando los descriptores: lactancia materna, transtornos de la lactancia y terapia. Fueron encontrados diez estudios, dos de ellos de revisión sistemática de la literatura, siete ensayos clínicos controlados y randomizados, y un estudio cuasi-experimental. Los estudios analizados presentan resultados divergentes y no hay evidencias suficientes para recomendar la implementación de los tratamientos evaluados. Son necesarios más estudios controlados y randomizados para verificar terapias eficaces para el tratamiento de la ingurgitación mamaria.
\end{abstract}

\section{DESCRIPTORES \\ Lactancia materna \\ Trastornos de la lactancia \\ Terapéutica}

\footnotetext{
1 Fisioterapeuta. Doutoranda do Departamento Materno Infantil e Saúde Pública da Escola de Enfermagem de Ribeirão Preto da Universidade de São Paulo. Ribeirão Preto, SP, Brasil. ligiasousa@usp.br ²Enfermeira. Doutoranda do Departamento Materno Infantil e Saúde Pública da Escola de Enfermagem de Ribeirão Preto da Universidade de São Paulo. Ribeirão Preto, SP, Brasil. mari.tradu@gmail.com ${ }^{3}$ Enfermeira, Professora Doutora do Departamento Materno Infantil e Saúde Pública da Escola de Enfermagem de Ribeirão Preto da Universidade de São Paulo. Ribeirão Preto, SP, Brasil. nakano@eerp.usp.br ${ }^{4}$ Enfermeira, Professora Titular do Departamento Materno Infantil e Saúde Pública da Escola de Enfermagem de Ribeirão Preto da Universidade de São Paulo. Ribeirão Preto, SP, Brasil. flagomes@eerp.usp.br
} 


\section{INTRODUÇÃO}

Os primeiros dias após o nascimento definem o início e a manutenção da lactação, podendo surgir dificuldades que requerem suporte à mulher para o estabelecimento da autoconfiança e resolução das dificuldades apresentadas. Dentre os possíveis transtornos com que nos deparamos na prática inclui a queixa de baixa produção de leite, dor no mamilo e traumas mamilares, ingurgitamento mamário e até complicações como a mastite ${ }^{(1)}$.

Na amplitude das intercorrências comuns no período de lactação, o presente estudo tem como enfoque o ingurgitamento mamário. Como processo normal da lactogênese, a apojadura é designada por alguns autores como ingurgitamento fisiológico ${ }^{(2)}$, em que ocorre retenção de leite nos alvéolos evoluindo para uma distensão alveolar e compressão dos ductos mamários causando obstrução ao fluxo de leite, que fica estagnado e evolui para edema secundário à estase vascular e linfática ${ }^{(3)}$. Em consequência ao aumento da pressão intraductal, o acúmulo de leite sofre transformação intermolecular e torna-se mais viscoso ${ }^{(3)}$, sendo popularmente conhecido como leite empedrado.

O ingurgitamento patológico é caracterizado pela distensão tecidual excessiva e consequente aumento no tamanho das mamas com presença de dor, hiperemia local, edema mamário e mamilos achatados que dificultam a pega do recémnascido. A puérpera pode apresentar grande desconforto, febre e mal-estar ${ }^{(3)}$. Quando não ocorre intervenção de alívio do ingurgitamento, a produção de leite é interrompida e inicia-se um processo de reabsorção, associado ao desmame precoce ${ }^{(4)}$. $O$ ingurgitamento mamário pode evoluir para mastite, um processo infeccioso agudo das glândulas mamárias, com achados clínicos como inflamação, febre, calafrios, mal-estar geral, astenia, prostração, abscessos mamários e septicemia ${ }^{(5)}$.

São encontrados sintomas variados de ingurgitamento entre $89 \%^{(5)}$ e $28,3 \%{ }^{(6)}$ das puérperas, sendo que, $20 \%$ das nutrizes apresentam ingurgitamento na primeira semana após nascimento ${ }^{(5,7)}, 46 \%$ entre a segunda e quarta semana, $23 \%$ após a quarta semana e apenas $11 \%$ não apresentam ingurgitamento mamário( ${ }^{(5)}$.

Os fatores de risco para o ingurgitamento mamário patológico estão relacionados ao início tardio da amamentação, mamadas não frequentes e de pouca duração, utilização de suplementos, sucção ineficaz do recém-nascido ${ }^{(3)}$, aumento repentino da produção de leite( ${ }^{(8)}$, lesão mamilar, que tem como um dos fatores determinantes a inadequada posição da criança durante a amamentação e apreensão do mamilo(9).
As mamadas em horários pré-determinados, controle de tempo da sucção, uso de sustentadores apertados para mama, uso de mamadeiras, não esvaziamento do leite restante após as mamadas nos primeiros dias e recém-nascido sonolento ou prematuro interferem no esvaziamento da mama e permitem o surgimento do ingurgitamento mamário(10).

Um grande problema encontrado em relação ao ingurgitamento mamário diz respeito às mulheres soropositivas para o HIV, as quais são orientadas a não amamentarem seus filhos para evitar a transmissão viral via leite materno e que, na maioria das vezes, apresentam sintomas de desconforto e dor provocados pelo ingurgitamento mamário(11).

A literatura aponta para o fato da maioria das nutrizes considerarem problemas no período de amamentação como normal e, desta maneira, sofrem desnecessariamente, pois a maioria das condições podem ser resolvidas com tratamentos adequados. Em estudo de abordagem qualitativa sobre os significados atribuídos pelas mulheres frente ao ingurgitamento mamário, identificou-se que os sinais de peitos cheios de leite, culturalmente, valorizam a mulher, qualificando-a como nutriz e não indicam anormalidade $^{(12)}$.

Há uma falta de conhecimento por parte das nutrizes em relação aos cuidados que podem ser tomados para evitar ou tratar mamas ingurgitadas, já que, aproximadamente $57 \%$ não sabem o que pode ser feito para alívio dos sintomas de ingurgitamento, 23,7\% conhecem a compressa quente ou massagem, $11,7 \%$ a ordenha, $6,4 \%$ colocam o recém-nascido para mamar, $0,8 \%$ usam medicamentos e $0,4 \%$ suspendem a amamentação na presença de ingurgitamento mamário(10).

Tradicionalmente, o tratamento do ingurgitamento mamário deve ser baseado na manutenção da amamentação e na ordenha manual sistemática para equilíbrio entre produção e consumo pela criança. Reforçam-se as mamadas frequentes e sob livre demanda, além de orientações à mãe a respeito da pega e sucção correta. Atrelados a estas condutas outros procedimentos isolados ou associados são comuns na prática cotidiana dos profissionais de saúde, com uso de protocolos variados, controversos e sem evidências científicas da eficácia dos procedimentos.

Desta maneira, o objetivo desta revisão integrativa é identificar e analisar as evidências encontradas na literatura a respeito da terapêutica não-farmacológica para alívio de sintomas de ingurgitamento mamário em puérperas em processo de amamentação. 


\section{MÉTODO}

O método de pesquisa utilizado foi a revisão integrativa da literatura que apresenta a síntese de múltiplos estudos publicados, permite identificar, avaliar e sintetizar os conhecimentos produzidos sobre determinado tema e possibilita conclusões gerais a respeito de uma área específica de estudo, visando à busca de evidências científicas e o aprofundamento do tema para a prática clínica ${ }^{(13)}$.

O percurso metodológico seguiu as seguintes etapas: definição dos objetivos e tema norteador, estabelecimento dos critérios de inclusão para seleção da amostra, seleção dos dados extraídos das pesquisas selecionadas, análise, discussão e apresentação dos resultados ${ }^{(13)}$. Para a busca da literatura inicialmente foi feita a identificação do tema e formulação da questão norteadora. Nesta revisão o tema norteador foi o uso de terapias não-farmacológicas no alívio de ingurgitamento mamário durante a amamentação. Foi utilizada a seguinte questão norteadora: Quais são as evidências disponíveis na literatura sobre o uso clínico de terapias não-farmacológicas no alívio do ingurgitamento mamário durante o aleitamento materno?
Os critérios de inclusão dos artigos definidos para a revisão foram: estudos que trataram especificamente o tema norteador da pesquisa, ou seja, o uso de terapias não-farmacológicas, isoladas ou associadas a outras técnicas de tratamento para alívio do ingurgitamento mamário; nos idiomas português, inglês e espanhol; publicados entre 1990 e 2010; com os resumos disponíveis nas bases de dados selecionadas; encontrados nas Bases de Dados: MEDLINE e LILACS. A busca foi realizada por acesso online. Os descritores controlados utilizados foram aleitamento materno, transtorno da lactação e terapia.

Foram incluídos na revisão integrativa artigos publicados cujas metodologias pudessem atingir evidência forte $(1,2$, e 3$)$, ou seja, revisões sistemáticas de múltiplos ensaios clínicos controlados randomizados, ensaios clínicos controlados randomizados ou estudos com delineamento de pesquisa quase-experimental ${ }^{(14)}$.

Para a análise, todos os artigos incluídos na amostra foram lidos na íntegra e categorizados a partir de um instrumento de coleta de dados, já submetido à validação(15), sendo extraídos dos artigos dados referentes à identificação do artigo/autores, tipo de revista científica, características metodológicas, avaliação das intervenções mensuradas e dos resultados encontrados.

Quadro1 - Artigos de revisão sistemática incluídos na revisão integrativa

\begin{tabular}{|c|c|c|c|c|}
\hline $\begin{array}{l}\text { Autores/ } \\
\text { Data }\end{array}$ & $\begin{array}{l}\text { Inclusão da revisão } \\
\text { sistemática }\end{array}$ & $\begin{array}{l}\text { Intervenções } \\
\text { Avaliadas }\end{array}$ & Resultados & Evidência \\
\hline $\begin{array}{l}\text { Mangesi, } \\
\text { Dowswell } \\
(2010)^{(16)}\end{array}$ & $\begin{array}{l}\text { Oito ensaios clínicos } \\
\text { controlados } \\
\text { randomizados, com total } \\
\text { de } 744 \text { mulheres } \\
\text { amamentando e com } \\
\text { sintomas de } \\
\text { ingurgitamento mamário, } \\
\text { entre os anos de } 1965 \text { e } \\
2007\end{array}$ & $\begin{array}{l}\text { A presente revisão sistemática } \\
\text { avaliou a acupuntura versus } \\
\text { cuidados rotineiros; folhas de } \\
\text { repolho fria versus folha de } \\
\text { repolho em temperatura } \\
\text { ambiente; folha de repolho } \\
\text { versus compressa fria; compressa } \\
\text { fria versus cuidados rotineiros; } \\
\text { tabletes de complexo de } \\
\text { protease versus placebo; ultra- } \\
\text { som terapêutico versus ultra-som } \\
\text { placebo; ocitocina subcutânea } \\
\text { versus placebo }\end{array}$ & $\begin{array}{l}\text { Ultra-som terapêutico, folha de } \\
\text { repolho e ocitocina subcutânea não } \\
\text { apresentaram diferenças } \\
\text { estatísticas significantes em relação } \\
\text { à resolução rápida dos sintomas. } \\
\text { Um estudo mostrou que a } \\
\text { acupuntura foi mais efetiva que os } \\
\text { cuidados de rotina no dia seguinte } \\
\text { ao tratamento, porém seis dias } \\
\text { após o início do tratamento os } \\
\text { resultados foram semelhantes. As } \\
\text { compressas frias não causaram } \\
\text { danos, associou-se com melhora } \\
\text { dos sintomas, embora as diferenças } \\
\text { entre o grupo controle e } \\
\text { intervenção na linha de base } \\
\text { dificultam as interpretações dos } \\
\text { dados }\end{array}$ & Nível 1 \\
\hline $\begin{array}{l}\text { Snowden, } \\
\text { Renfrew, } \\
\text { Woolridge } \\
(2001)^{(17)}\end{array}$ & $\begin{array}{l}\text { Oito ensaios clínicos } \\
\text { controlados randomizados } \\
\text { envolvendo } 424 \text { mulheres } \\
\text { em processo de } \\
\text { amamentação e com } \\
\text { sintomas de } \\
\text { ingurgitamento mamário. }\end{array}$ & $\begin{array}{l}\text { Recursos farmacológicos: Dansen } \\
\text { versus placebo; ocitocina versus } \\
\text { placebo; protease versus } \\
\text { placebo. Recursos não- } \\
\text { farmacológicos: extrato da folha } \\
\text { de repolho versus placebo; ultra- } \\
\text { som terapêutico versus placebo; } \\
\text { folha de repolho fria versus folha } \\
\text { de repolho em temperatura } \\
\text { ambiente; folha de repolho } \\
\text { versus compressa fria; bolsa de } \\
\text { gelo versus nenhum tratamento }\end{array}$ & $\begin{array}{l}\text { Não foram encontrados resultados } \\
\text { benéficos para os artigos que } \\
\text { utilizaram a folha ou extrato de } \\
\text { repolho. O ultrasom terapêutico e } \\
\text { placebo foram igualmente eficazes. } \\
\text { O uso de Danzen e de protease } \\
\text { melhoraram significativamente os } \\
\text { sintomas do ingurgitamento } \\
\text { quando comparados ao placebo. A } \\
\text { ocitocina e a compressa fria não } \\
\text { tiveram nenhum efeito } \\
\text { demonstrável sobre sintomas de } \\
\text { ingurgitamento. } \\
\text { As folhas de repolho foram } \\
\text { igualmente eficazes à compressa } \\
\text { fria }\end{array}$ & Nível 1 \\
\hline
\end{tabular}


Os resultados obtidos foram discutidos de forma descritiva, a fim de comparar os resultados positivos e negativos e fornecer subsídios à prática clínica baseada em evidências.

\section{RESULTADOS}

Durante a busca dos artigos da presente revisão integrativa, de acordo com os critérios de inclusão previamente estabelecidos, foram encontrados dez estudos que tratavam do tema abordado. Destes, todos os artigos foram encontrados na base de dados MEDLINE e nenhum artigo na base de dados LILACS. Abaixo, apresenta-se um panorama geral dos artigos analisados.

Dentre os artigos encontrados, dois foram publicados em revista de enfermagem geral, um em revista de enfermagem especializada em obstetrícia, um em revista de fisioterapia, quatro foram publicados em revistas da área da saúde referente à amamentação e nascimento e dois foram de revisão sistemática e publicados na Biblioteca Cochrane.

Quadro 2 - Artigos de ensaio clínico incluídos na revisão integrativa

\begin{tabular}{|c|c|c|c|c|}
\hline Autores/Data(18) & Participantes & Intervenção & Resultados & Evidência \\
\hline Chiu et al. (2010) & $\begin{array}{l}54 \text { mulheres no período pós- } \\
\text { parto, amamentando e com } \\
\text { diagnóstico de } \\
\text { ingurgitamento mamário }\end{array}$ & $\begin{array}{l}\text { Terapia Gua-Sha } \\
\text { (experimental) versus } \\
\text { compressa quente e } \\
\text { massagem (controle) }\end{array}$ & $\begin{array}{l}\text { No grupo experimental, a } \\
\text { temperatura corporal e das } \\
\text { mamas baixaram após } 5 \\
\text { minutos, e houve melhora das } \\
\text { escalas de ingurgitamento, dor } \\
\text { e desconforto. Após } 30 \\
\text { minutos, mantiveram-se os } \\
\text { resultados. }\end{array}$ & Nível 2 \\
\hline $\begin{array}{l}\text { Arora, Vatsa, Dadhwal } \\
(2008)^{(7)}\end{array}$ & $\begin{array}{l}60 \text { mulheres no período pós- } \\
\text { parto, em amamentação } \\
\text { ecom ingurgitamento } \\
\text { mamário }\end{array}$ & $\begin{array}{l}\text { Folha de repolho fria versus } \\
\text { compressa fria e quente } \\
\text { (aplicadas alternadamente) }\end{array}$ & $\begin{array}{l}\text { Ambos os tratamentos } \\
\text { diminuíram o ingurgitamento } \\
\text { mamário. Porém, a compressa } \\
\text { fria e quente foi mais efetiva } \\
\text { no alívio da dor. }\end{array}$ & Nível 3 \\
\hline Kvist et al. $(2007)^{(19)}$ & $\begin{array}{l}205 \text { mulheres em processo } \\
\text { de amamentação e com } \\
\text { sintomas inflamatórios da } \\
\text { mama (eritema, aumento da } \\
\text { tensão nas mamas, febre, } \\
\text { dor e resistência do tecido } \\
\text { mamário durante a } \\
\text { lactação) }\end{array}$ & $\begin{array}{l}\text { Cuidados essenciais e spray } \\
\text { nasal de ocitocina versus } \\
\text { cuidados essenciais e } \\
\text { acupuntura em dois pontos } \\
\text { versus cuidados essenciais e } \\
\text { acupuntura em três pontos }\end{array}$ & $\begin{array}{l}\text { Mulheres que receberam a } \\
\text { acupuntura tiveram } \\
\text { significativamente menos } \\
\text { gravidade dos sintomas. A } \\
\text { acupuntura pode ser uma } \\
\text { escolha mais conveniente e } \\
\text { menos invasiva que o uso do } \\
\text { spray nasal de ocitocina }\end{array}$ & Nível 2 \\
\hline Kvist et al. $(2004)^{(20)}$ & $\begin{array}{l}88 \text { mulheres lactantes com } \\
\text { sintomas inflamatórios de } \\
\text { mama (eritema, tensão e dor } \\
\text { mamária) }\end{array}$ & $\begin{array}{l}\text { Acupuntura em dois pontos } \\
\text { versus acupuntura em três } \\
\text { pontos versus tratamento } \\
\text { convencional } \\
\text { (aconselhamento sobre } \\
\text { intervalo e duração da } \\
\text { mamada, esvaziamento } \\
\text { manual das mamas, bomba } \\
\text { ou banho quente, aplicação } \\
\text { de algodão e uso de spray } \\
\text { nasal de ocitocina). Os } \\
\text { grupos de acupuntura } \\
\text { podiam fazer uso dos } \\
\text { tratamentos convencionais, } \\
\text { usado como forma de } \\
\text { avaliação da efetividade da } \\
\text { acupuntura }\end{array}$ & $\begin{array}{l}\text { Não houve diferença } \\
\text { significativa entre os grupos } \\
\text { para o número de mulheres que } \\
\text { usaram os recursos de } \\
\text { tratamento convencional por } \\
\text { mais de três dias para a } \\
\text { recuperação, nem para os seus } \\
\text { índices de gravidade no mesmo } \\
\text { período }\end{array}$ & Nível 2 \\
\hline $\begin{array}{l}\text { Roberts, Reiter, Schuster } \\
(1995)^{(21)}\end{array}$ & $\begin{array}{l}28 \text { lactantes com presença } \\
\text { de dor nas mamas devido ao } \\
\text { ingurgitamento mamário }\end{array}$ & $\begin{array}{l}\text { Folha de repolho resfriada } \\
\text { versus folha de repolho em } \\
\text { temperatura ambiente por } \\
\text { duas horas de tratamento em } \\
\text { ambos os grupos }\end{array}$ & $\begin{array}{l}\text { Os dois grupos apresentaram } \\
\text { significante redução da dor, } \\
\text { porém, não houve diferença } \\
\text { significativa no alívio da dor } \\
\text { após o tratamento entre os } \\
\text { grupos. Para os autores, isto } \\
\text { sugere que a temperatura da } \\
\text { folha de repolho não interfere } \\
\text { no alívio da dor }\end{array}$ & Nível 2 \\
\hline Roberts $(1995)^{(22)}$ & $\begin{array}{l}34 \text { lactantes com } \\
\text { ingurgitamento mamário }\end{array}$ & $\begin{array}{l}\text { Folha de repolho verde } \\
\text { resfriada versus bolsa de gel } \\
\text { resfriada, por período de até } \\
\text { oito horas, para alívio da dor } \\
\text { em mamas ingurgitadas }\end{array}$ & $\begin{array}{l}\text { Houve redução } \\
\text { estatisticamente significativa } \\
\text { da dor para ambos os } \\
\text { tratamentos, sendo que } 68 \% \\
\text { das mulheres obtiveram alívio } \\
\text { da dor uma a duas horas após o } \\
\text { início do tratamento. A maioria } \\
\text { das mulheres preferiram a } \\
\text { folha de repolho }\end{array}$ & Nivel 2 \\
\hline
\end{tabular}


...continuação

\begin{tabular}{l|l|l|l|l}
\hline Autores/Data & Participantes & Intervenção & Eesultados \\
\hline $\begin{array}{l}\text { Nikodem et al. } \\
(1993)^{(23)}\end{array}$ & $\begin{array}{l}120 \text { mulheres em processo } \\
\text { de amamentação com } \\
\text { ingurgitamento mamário } 72 \\
\text { horas após o nascimento }\end{array}$ & $\begin{array}{l}\text { Folha de repolho versus os } \\
\text { cuidados de rotina para } \\
\text { alívio do ingurgitamento } \\
\text { mamário. }\end{array}$ & $\begin{array}{l}\text { O grupo que utilizou a folha de } \\
\text { repolho apresentou maior } \\
\text { porcentagem de amamentação } \\
\text { exclusiva em seis semanas e } \\
\text { menos sintomas de } \\
\text { ingurgitamento mamário, mas } \\
\text { o resultado não foi } \\
\text { estatisticamente significativo }\end{array}$ \\
McLachlan et al. (1991) & $\begin{array}{l}\text { (24) } \\
\text { e com ingurgitamento } \\
\text { mamário }\end{array}$ & $\begin{array}{l}\text { Ultra-som terapêutico versus } \\
\text { ultra-som placebo (aparelho } \\
\text { desligado) no alívio da dor e } \\
\text { rigidez mamária }\end{array}$ & $\begin{array}{l}\text { Olacebo não reduziram os } \\
\text { slintomas de ingurgitamento. O } \\
\text { ultra-som proporcionou maior } \\
\text { alívio da dor, que pode ser } \\
\text { justificada pelo efeito de } \\
\text { aquecimento produzido pelo } \\
\text { aparelho. }\end{array}$ \\
\hline
\end{tabular}

Em relação ao tipo de delineamento de pesquisa, dois foram estudos de revisão sistemática da literatura, sete ensaios clínicos controlados randomizados e um estudo de metodologia quase-experimental. Desta maneira, em relação à força das evidências dos artigos, destacam-se dois artigos com nível de evidência 1, sete com nível de evidência 2 e um artigo com nível de evidência 3.

Os Quadros 1 e 2 apresentam os principais dados encontrados nos artigos avaliados referente aos autores, ano de publicação, delineamento de pesquisa, intervenção estudada, resultados e nível de evidência.

\section{DISCUSSÃO}

Em relação ao objetivo da pesquisa, ou seja, uso de terapias não-farmacológicas para alívio do ingurgitamento mamário, identificamos, de acordo com os critérios de inclusão pré-estabelecidos, os seguintes recursos terapêuticos: acupuntura, compressa quente associada à massagem, compressa quente e fria aplicadas alternadamente, compressa fria, folha de repolho e ultra-som terapêutico.

As revisões sistemáticas da literatura apresentadas sobre o tema estudado, abordaram, além dos recursos não-farmacológicos, alguns agentes farmacológicos para alívio dos sintomas de ingurgitamento mamário, que não foram objeto do presente estudo. Todavia, os fármacos apresentados em revisão sistemática da literatura ${ }^{(16-17)}$ mostraram resultados positivos, porém mais discussões sobre efeitos colaterais de medicamentos utilizados para mama ingurgitada devem ser estudados, especificando, inclusive, a ingestão dos medicamentos pelo recém-nascido através do leite materno.

Os artigos analisados, em sua maioria, compararam os recursos terapêuticos a outros recursos ou tratamento convencional (massagem, esvaziamento mamário, orientações, entre outros). Isto pode ter prejudicado a interpretação dos resultados ao identificar se a técnica estudada era de fato efetiva, comparando-a a um grupo controle ou placebo. Apenas um estudo que utilizou o ultra-som nas mamas ingurgitadas utilizou um grupo placebo e não apresentou melhora dos sinais e sintomas. Este estudo obteve apenas alívio da dor, que, segundo os próprios autores se deve ao aquecimento profundo gerado pelas ondas do ultra-som, não justificando seu uso para tratamento de ingurgitamento mamário ${ }^{(24)}$.

A aplicação da folha de repolho em diferentes níveis de temperatura é uma técnica descrita na literatura para tratamento de mamas ingurgitadas. Entretanto os estudos apresentam resultados conflitantes e, nenhum deles utilizou grupo placebo ou controle sem tratamento ${ }^{(7,21-23)}$. Além disso, podemos discutir se os efeitos produzidos no alívio de sintomas ou de dor secundário ao ingurgitamento se devem à folha de repolho ou à temperatura em que esta é aplicada, já que um estudo encontrou resultados semelhantes ao aplicar a folha de repolho resfriada e a bolsa de gel fria ${ }^{(22)}$.

Outro aspecto que nos leva a um questionamento em relação ao uso da folha de repolho na prática clínica é a necessidade de esterilização efetiva da folha para evitar o surgimento e proliferação bacteriana, desencadeando processo infeccioso, via poro mamilar ou trauma.

A aplicação de calor local diretamente nas mamas ingurgitadas promove vasodilatação, desta maneira gera um aumento da circulação e consequente aumento no volume de leite nas mamas, o que, fisiologicamente, levaria ao aumento de ingurgitamento ${ }^{(4)}$. Entretanto, nenhum estudo buscou pesquisar a compressa quente especificamente. Ela foi utilizada em associação com a massagem, não mostrando resultados efetivos quando comparada a terapia de pressão nas mamas (Terapia Gua-Sha)(18). A compressa quente foi usada, também, alternadamente com a compressa fria, mostrando-se mais efetiva para alívio da dor quando comparada ao uso de folhas de repolho, embora este tenha sido um estudo quase-experimental ${ }^{(7)}$. 
A compressa fria é responsável pela redução da produção de leite quando aplicada sobre a mama ingurgitada. O frio provoca uma vasoconstricção temporária que leva a diminuição do fluxo sanguíneo, do edema e da drenagem linfática, tendo como efeito uma menor produção de leite ${ }^{(4)}$. Nos artigos apresentados a compressa fria mostrou-se efetiva para aliviar a dor, porém resultados sobre a produção de leite após seu uso não foram apresentados.

A acupuntura apresentou efetiva diminuição dos sintomas do ingurgitamento mamário, destacando seu uso na prática clínica, pois não apresentou efeitos colaterais, em especial quando comparado ao uso de spray nasal de ocitocina ${ }^{(19)}$. Entretanto, a solicitação das puérperas para uso de recursos convencionais foi usado de maneira semelhante para os grupos que usaram a acupuntura ou para aqueles que fizeram uso apenas do tratamento convencional ${ }^{(20)}$.

A Terapia Gua-Sha refere-se à raspagem da pele com pressão até surgir petéquias no trajeto dos pontos. O movimento é realizado sete vezes a cada ciclo, repetindo dois ciclos, durando 2 minutos. Esta técnica mostrou-se efetiva para alívio dos sinais e sintomas do ingurgitamento mamário quando comparado a massagem associada à compressa quente. Segundo os autores desta pesquisa, este recurso é fácil de ser aplicado e de baixo custo, viabilizando uma técnica não-farmacológica adequada para casos de mama ingurgitada, em que o profissional pode ajudar as mulheres física e psicologicamente ${ }^{(18)}$.

Em revisão sistemática da literatura, algumas técnicas mostraram-se promissoras para o tratamento do ingurgitamento mamário, porém, não há evidências suficientes para os estudos analisados por estes autores que justifique uma implementação difusa de alguma técnica descrita. Estes autores concluíram que a qualidade de evidência dos estudos incluídos na revisão não é alta. A maioria dos estudos não tem poder estatístico suficiente para detectar diferenças entre os grupos e então os resultados não são conclusivos. Desta maneira, não há evidências suficientes para recomendar a implementação dos tratamentos avaliados em larga escala(16).

Quanto aos instrumentos de avaliação do ingurgitamento mamário, os estudos analisados utilizaram a descrição visual, identificação de enrijecimento mamário, identificação da temperatura das mamas e avaliação dos sintomas e da dor causados pelo ingurgitamento. Para isto, estudos utilizaram a escala visual analógica da dor e a escala numérica da dor. A falta de padronização em relação aos aspectos de avaliação dos estudos pode dificultar a análise dos benefícios dos recursos utilizados.

Sobre os cuidados dos profissionais de saúde durante o período puerperal, é importante destacarmos que a maneira mais eficaz para reduzir a incidência de ingurgitamento mamário durante o puerpério imediato é a prevenção, que pode ser feita pela efetiva remoção de leite excedente após as mamadas ${ }^{(3)}$. As práticas de orientação e auxílio da equipe de enfermagem podem afetar diretamente a produção de leite e, consequentemente, a amamentação. O contato pele-a-pele associado à sucção precoce promove aumento na produção e ingestão de leite até quatro dias após o nascimento e proporciona resultado positivo na duração da amamentação(25).

Aplicar orientação única às técnicas de aleitamento materno antes da alta-hospitalar não apresentam resultados positivos na prevenção do ingurgitamento. $O$ ingurgitamento está presente em 35,1\% das mulheres sete dias após a sessão única de orientação e em $37,8 \%$ após 30 dias da orientação. Mulheres sem qualquer orientação em relação à amamentação na maternidade apresentam 34,3\% e $36,5 \%$ de ingurgitamento mamário, sete e trinta dias após a alta-hospitalar, respectivamente ${ }^{(26)}$. Estes dados evidenciam a necessidade de orientações eficazes e continuadas sobre técnicas e práticas de amamentação, as quais deveriam iniciar-se no pré-natal e serem seguidas durante as primeiras semanas pós-parto.

Programas relacionados à orientação da promoção do aleitamento materno, criação de estratégias que aumentam o conhecimento das nutrizes, apoio regular e suporte as mulheres durante o processo de amamentação são efetivos para a manutenção do aleitamento materno exclusivo. Autores observam a necessidade de uma aproximação do contexto cultural familiar de mulheres em situação de aleitamento visto que as dificuldades na prática da amamentação muitas vezes ocorrem em função da inexistência de um suporte adequado do serviço de saúde, ou seja, centram sua prática na dimensão biológica subestimando abordagens que considerem os condicionantes psicológicos, sociais e culturais ${ }^{(27)}$.

Nesta perspectiva, problemas detectados durante a amamentação seriam reduzidos ou extintos através de atitudes e posturas humanizadas como a participação ativa e orientada dos acompanhantes no pré-natal e puerpério, que evitaria o uso de recursos abusivos, tais como excesso de medicamentos a mulher ${ }^{(28)}$.

Todavia, depois de instalado um quadro de ingurgitamento mamário, recursos adequados são fundamentais para seu tratamento e manutenção do aleitamento materno exclusivo até os seis meses do recém-nascido, de acordo com o Ministério da Saúde.

Isso nos remete à importância de estudos que visem analisar recursos não-farmacológicos para alívio do ingurgitamento mamário. Os artigos analisados na presente revisão integrativa apresentam evidências fortes, mas ainda há falta de concordância sobre qual terapia poderia trazer maiores benefícios à puérpera com mamas ingurgitadas. Um importante aspecto observado dentre os estudos analisados é a falta de citação a respeito das opiniões das participantes e suas preferências quanto às opções de tratamento. 
A presente revisão sugere aos profissionais de saúde utilizar recursos com bases nas evidências científicas apresentadas na literatura. Os dados encontrados permitem recomendar a acupuntura e a terapia Gua-Sha como recursos não-farmacológicos que podem substituir com segurança o uso de terapias medicamentosas às mulheres em processo de amamentação. Em relação aos demais recursos, entendemos que alguns, que são inclusive utilizados na prática clínica, podem causar piora dos sintomas de ingurgitamento mamário, como, por exemplo, a aplicação de calor pela fisiologia de sua ação já citada anteriormente ou o uso da folha de repolho, a qual não apresenta estudos relatando as possibilidades de infecção com seu uso. Podemos afirmar que recursos não-farmacológicos são bem vindos para aliviar ingurgitamento mamário, porém, observamos a necessidade de mais pesquisas nessa área para que estes recursos possam contribuir para os cuidados com a saúde da puérpera e, desta maneira, realizar uma prática mais humanizada desde a gestação até a fase puerperal.

\section{REFERÊNCIAS}

1. Castro KF, Souto CMRM, Rigão TVC, Garcia TR, Bustorff LACV, Braga VAB. Intercorrências mamárias relacionadas à lactação: estudo envolvendo puérperas de uma maternidade públicade João Pessoa, PB. Mundo Saúde. 2009;33(4):433-9.

2. Morais AEP, Thomson Z. Manejo clínico da amamentação no domicílio. In: Issler H. O aleitamento materno no contexto atual: políticas, práticas e bases científicas. São Paulo: Sarvier; 2008.

3. Giugliani ERJ. Problemas comuns na lactação e seu manejo. J Pediatria. 2004;80(5 Supl):147-54.

4. Academy of Breastfeeding Medicine Protocol Committee; Berens P. ABM clinical protocol \#20: Engorgement. Breastfeed Med. 2009;4(2):111-3.

5. Sales AN, Vieira GO, Moura MSQ, Almeida SPTMA, Vieira TO. Mastite puerperal: estudo de fatores predisponentes. Rev Bras Ginecol Obstet. 2000;22(10):627-32.

6. Fernandes RAQ, Lara ACL. Amamentação: auxiliando as mães no domicílio, após a alta hospitalar. Online Braz J Nurs (Online).2006;5(2).

7. Arora S, Vatsa M, Dadhwal. A comparison of cabbage leaves vs. hot and cold compresses in the treatment of breast engorgement. Indian J Community Med. 2008;33(3):160-2.

8. Zorzi NT. Práticas utilizadas pelas puérperas nos problemas mamários. Rev Bras Enferm. 2006;59(4):521-6.

\section{CONCLUSÃO}

A maioria das dificuldades apresentadas durante a lactação, quando precocemente tratadas, é de fácil solução e resulta em experiências satisfatórias para a mulher e recém-nascido, visto que, a amamentação representa um importante processo após o nascimento, relacionado positivamente com a alimentação do recém-nascido e benefícios para a saúde da mulher. Além disso, a proximidade corporal estabelece uma relação de vínculo entre mãe e filho.

Seguindo esta linha de pensamento, observamos a necessidade de auxílio e técnicas de prevenção e tratamento nos problemas que afetam a amamentação, tais como o ingurgitamento mamário. Destacamos, principalmente, a elaboração de ensaios clínicos controlados e randomizados para alívio do ingurgitamento mamário em âmbito nacional, pois nenhuma pesquisa deste delineamento e com rigor metodológico foi encontrada, até o momento, sobre esta temática, sendo encontrados, em especial, estudos descritivos e de orientações e prevenção aos transtornos da lactação.

9. Coca KP, Gamba MA, Silva RS, Abrão ACFV. Does breastfeeding position influence the onset of nipple trauma? Rev Esc Enferm USP [Internet]. 2009 [cited 2010 Nov 21];43(2):446-52. Available from: http://www.scielo.br/ pdf/reeusp/v43n2/en_a26v43n2.pdf

10. Percegoni N, Araújo RMA, Silva MMS, Euclydes MP, Tinôco ALA. Conhecimento sobre aleitamento materno de puérperas atendidas em dois hospitais de Viçosa, Minas Gerais. Rev Nutr. 2002;15(1):29-35.

11. Machado MMT, Braga MQC, Galvão MTG. Problems with the puerperal breast revealed by HIV-infected mothers. Rev Esc Enferm USP [Internet]. 2010 [cited 2010 Nov 21];44(1):120-5. Available from: http://www.scielo.br/ pdf/reeusp/v44n1/en_a17v44n1.pdf

12. Nakano AMS. Vivências da amamentação para um grupo de mulheres: nos limites de ser o corpo para o filho e de ser o corpo para si [tese livre-docência]. Ribeirão Preto: Escola de Enfermagem de Ribeirão Preto, Universidade de São Paulo; 2003.

13. Mendes KDS, Silveira RCCP, Galvão CM. Revisão integrativa: método de pesquisa para a incorporação de evidências na saúde. Texto Contexto Enferm. 2008;17(4):758-64.

14. Melnyk BM. Finding and appraising systematic reviews of clinical interventions: critical skills for evidence-based practice. Pediatr Nurs. 2003;29(2):147-9. 
15. Ursi ES. Prevenção de lesões de pele no perioperatório: revisão integrativa da literatura [dissertação]. Ribeirão Preto: Escola de Enfermagem de Ribeirão Preto, Universidade de São Paulo; 2005.

16. Mangesi L, Dowswell T. Treatments for engorgement during lactation. Cochrane Database Syst Rev. 2010;(9):CD006946.

17. Snowden HM, Renfrew MJ, Woolridge MW. Treatments for engorgement during lactation. Cochrane Database System Rev. 2001;(2):CD000046.

18. Chiu JY, Gau ML, Kuo SY, Chang YH, Kuo SC, Tu HC. Effects of Gua-Sha Therapy on breast engorgement: a randomized controlled trial. J Nurs Res. 2010;18(1):1-10.

19. Kvist LJ, Hall-Lord ML, Rydhstroem H, Larsson BW. A randomized-controlled trial in Sweden of acupuncture and care interventions for the relief of inflammatory symptoms of the breast during lactation. Midwifery. 2007;23(2):184-95.

20. Kvist LJ, Larsson W, Hall-Lord ML, Rydhstroem H. Effects of acupuncture and care interventions on the outcome of inflammatory symptoms of the breast in lactating women. Int Nurs Rev. 2004;51(1):56-64.

21. Roberts KL, Reiter M, Schuster D. A comparison of chilled and room temperature cabbage leaves in treating breast engorgement. J Hum Lact. 1995;11(3):191-4.

22. Roberts KL. A comparison of chilled cabbage leaves and chilled gelpaks in reducing breast engorgement. J Hum Lact. 1995;11(1):17-20.
23. Nikodem VC, Danziger D, Gebka N, Gulmezoglu AM, Hofmeyr GJ. Do cabbage leaves prevent breast engorgement? A randomized, controlled study. Birth. 1993;20(2):61-4.

24. McLachlan Z, Milne EJ, Lumley J, Walker BL. Ultrasound treatment for breast engorgement: a randomised double blind trial. Aust J Physiother. 1991;37(1):23-8.

25. Bystrova $K$, Widström AM, Matthiesen AS, Ransjö-Arvidson AB, Welles-Nyström B, Vorontsov I, et al. Early lactation performance in primiparous and multiparous women in relation to different maternity home practices: a randomised trial in St. Petersburg. Int Breastfeed J [Internet]. 2007 [cited 2010 Nov 21];2:9. Available from: http:// www.ncbi.nlm.nih.gov/pmc/articles/PMC1878468/ pdf/1746-4358-2-9.pdf

26. Oliveira LD, Giugliani ERJ, Espírito Santo LC, França MCT, Weigert EML, Kohler CVF, et AL. Effect of intervention to improve breastfeeding technique on the frequency of exclusive breastfeeding and lactation-related problems. J Hum Lact. 2006;22(3):315-21.

27. Frota MA, Mamede AL, Vieira $\mathrm{L}$, de Albuquerque CM, Martins MC. Cultural practices about breastfeeding among families enrolled in a Family Health Program. Rev Esc Enferm USP [Internet]. 2009 [cited 2010 Nov 21];43(4):895-901. Available from: http://www.scielo.br/pdf/reeusp/v43n4/en_a22v43n4.pdf

28. Narchi NZ, Fernandes RAQ, Dias LA. Variables that influence the maintenance of exclusive breastfeeding. Rev EsC Enferm USP [Internet]. 2009 [cited 2010 Nov 21];43(1):87-94. Available from: http://www.scielo.br/ pdf/reeusp/v43n1/en_11.pdf 